\title{
Thermal gravity analysis for the study of stability of graphene oxide-glycine nanocomposites
}

\author{
F. Najafi ${ }^{1} \cdot$ M. Rajabi ${ }^{2}$
}

Received: 30 January 2015/Accepted: 8 May 2015/Published online: 30 May 2015

(c) The Author(s) 2015. This article is published with open access at Springerlink.com

\begin{abstract}
In this work, we synthesized graphene oxideglycine (GO-G) nanocomposite. To produce this nanocomposite with GO surface, glycine with known concentration was added to GO suspension in ethanol solvent. Nanocomposites provided were characterized by scanning electron microscope (SEM) and Fourier transform infrared (FT-IR) spectroscopy, respectively. Thermogravimetric analysis (TGA) was employed to investigate the thermal stability of these nanocomposites. Results of characterization by SEM and FT-IR showed that nanocomposite was created by the reaction between GO and G. Study of thermal stability by TGA showed that thermal stability of GO was more than that of the $\mathrm{GO}-\mathrm{G}$ nanocomposite.
\end{abstract}

Keywords Thermal stability - Nanocomposite · Graphene oxide $\cdot$ Glycine $\cdot$ Synthesis

\section{Introduction}

Graphene (Gr), a single layer of $s p^{2}$-hybridized carbon atoms in a closely packed honeycomb two-dimensional lattice, has attracted enormous attention since its discovery in 2004 [1]. Graphene, a new two-dimensional carbon nanomaterial and a fundamental building block for graphitic materials, has been the hotspot in multidisciplinary

\section{F. Najafi}

fahimnajafi@gmail.com

1 Department of Chemistry, Roudehen Branch, Islamic Azad University, Roudehen, Iran

2 Department of Chemistry, Arak Branch, Islamic Azad University, Arak, Iran field owing to its high surface area (surface/mass), excellent electrical behavior, and thermal properties [2-6].

One of the most commonly used derivatives of graphene is graphene oxide (GO). One of the important structural elements of graphite is GO that is conjunct together by van der Waals forces. GO has attracted a lot of attention because of its capability of being used in energy, electronics, water treatment membranes, etc. [7].

Glycine with the formula $\mathrm{NH}_{2} \mathrm{CH}_{2} \mathrm{COOH}$ (abbreviated as Gly or G) [8] is one of the organic compounds. Glycine is the smallest among amino acids usually found in proteins. With considering a hydrogen substituent assist sidechain [8]. Glycine is used as a biocompatible compound for the synthesis of many molecules [9] and for treating schizophrenia, benign prostatic hyperplasia (BPH), and some rare inherited metabolic disorders. It is also employed in memory enhancement and cancer prevention, and protects kidneys from the harmful side effects of certain drugs used after organ transplantation as well as the liver from the harmful effects of alcohol $[10,11]$.

Nanocomposite is a multiphase solid material in which one of the phases has one, two, or three dimensions of lower than $100 \mathrm{~nm}$ [11], or structures having nanoscale repeat distances between the different phases that make up the material [11]. Graphene oxide-glycine (GO-G) nanocomposites can be used in adsorption process and other applications.

In this study, we have synthesized GO-G nanocomposites. To produce this nanocomposite of GO sheets, glycine with known concentration was added to GO suspension in ethanol solvent. Nanocomposites provided were characterized by scanning electron microscope (SEM) and Fourier transform infrared spectroscopy (FTIR), respectively. Thermogravimetric analysis (TGA) was employed to investigate the thermal stability of these nanocomposites. 


\section{Materials and methods}

\section{Materials}

\section{Graphene oxide}

GO used in this work was provided by "nanocs" company -graphene (USA) with a purity of over $90 \%$. The GO used was a dry powder with the following characteristics: color: brown, composition: carbon (79\%), oxygen (20\%), flake size: $0.5-5$ microns, thickness: 1 atomic layer-at least $80 \%$ (Fig. 1).

\section{Glycine}

Glycine used in this work was provided by Sigma-Aldrich Company with a purity of more than $99 \%$. The glycine used possessed the following characteristics: CAS number: 56-40-6, impurities: $\leq 0.01 \%$ insoluble matter, pKa $\left(25^{\circ} \mathrm{C}\right): 2.35$ and m.p.: $240{ }^{\circ} \mathrm{C}$ (dec.) (lit.).

\section{Preparation of graphene oxide-glycine nanocomposites}

GO-G nanocomposites were prepared according to the following method: $45 \mathrm{mg}$ of dry powder of GO and $80 \mathrm{mg}$ of glycine were dissolved in ethanol and shaken well until the solution becomes even. Then $50 \mathrm{mg}$ of 1-ethyl(3,3-dieamino-propel acetate) Carobo amide $99 \%$ (EDC) was added to initiate the reaction between $\mathrm{GO}$ and glycine (with purity $\geq 99 \%$ provided by Aldrich Company). Then $25 \mathrm{mg}$ of $N$-hydroxyl $99.9 \%$ (Aldrich Company) was added to the above mixture and refluxed for $36 \mathrm{~h}$ at $70{ }^{\circ} \mathrm{C}$. After 2 days, GO-G nanocomposites were prepared, and using a vacuum

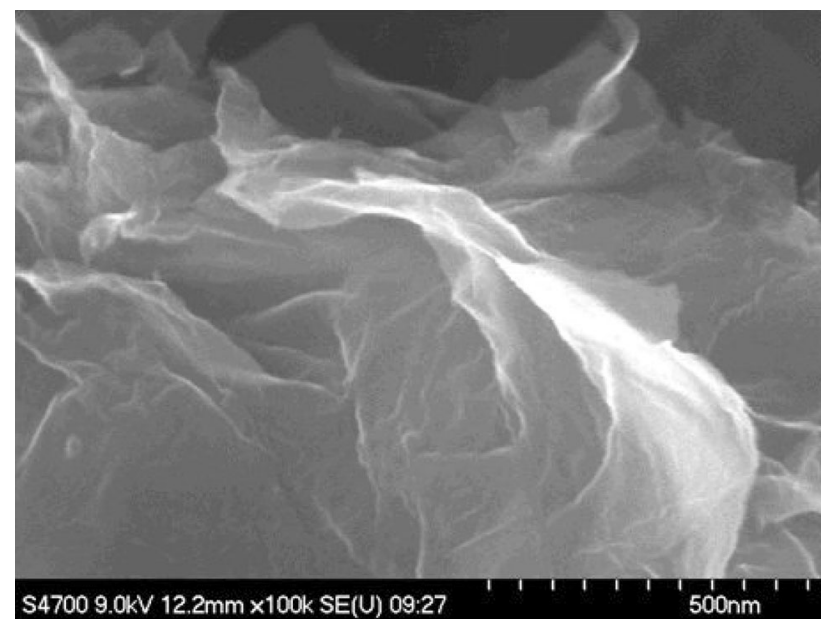

Fig. 1 Scanning electron microscope (SEM) for graphene oxide (GO) pump and micro-cellulose paper with a pore size $22 / 0$ micrometer, these nanocomposites were separated from other materials and the deposit was washed with ethanol and water mixture in equal proportions until the $\mathrm{pH}$ of the water coming out of the filter paper becomes neutral. After GO-G nanocomposites were formed, they were placed in vacuum oven for 1 day at $45^{\circ} \mathrm{C}$ to dry completely.

\section{Results and discussion}

\section{Characterization of GO-G nanocomposites}

FT-IR spectroscopies of the GO and GO-G nanocomposites are shown in Figs. 2 and 3.

As shown in Fig. 3 for GO, the peak at $1084 \mathrm{~cm}^{-1}$ is attributed to the $(\mathrm{C}-\mathrm{O})$ stretching, peak at $1387 \mathrm{~cm}^{-1}$ is attributed to the $(\mathrm{C}-\mathrm{O})$ bending, band at $1627 \mathrm{~cm}^{-1}$ is assigned to vibrations of the carbon-carbon double bond, small band at $1726 \mathrm{~cm}^{-1}$ is assigned to the ketone double bond vibrations $(\mathrm{C}=\mathrm{O})$, peak at $2362 \mathrm{~cm}^{-1}$ is attributed to the carboxylic group, peaks at $2849 \mathrm{~cm}^{-1}$ and $2921 \mathrm{~cm}^{-1}$ are attributed to the $(\mathrm{C}-\mathrm{H})$ bending vibrations and $\mathrm{O}-\mathrm{H})$ peak is also seen at $3434 \mathrm{~cm}^{-1}$ position [11-13].

As observed in Fig. 3, the intensity of the peak of carboxylic group was reduced, because of its reaction with glycine. Also the peak formed at $1555 \mathrm{~cm}^{-1}$ confirms the presence of an imide functional group in the nanocomposite.

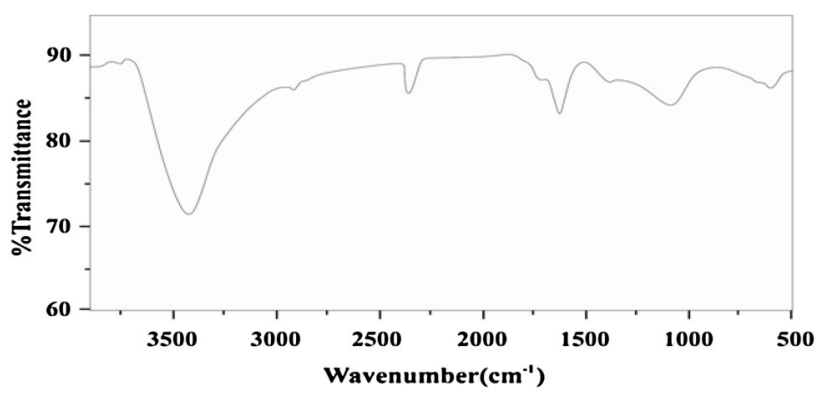

Fig. 2 FT-IR of graphene oxide surface

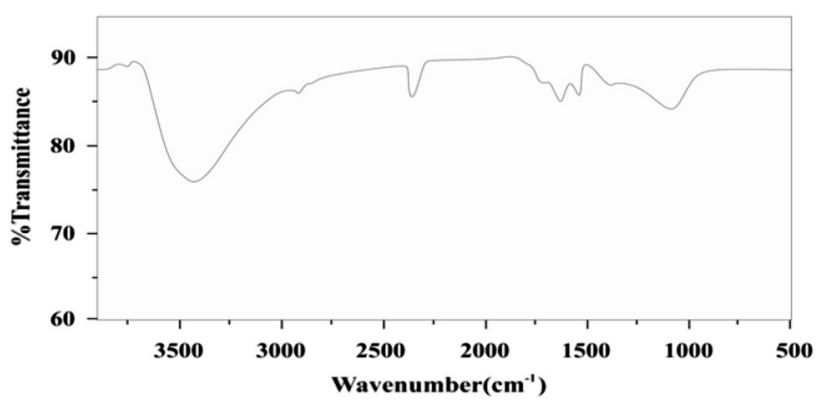

Fig. 3 FT-IR of graphene oxide-glycine nanocomposites 


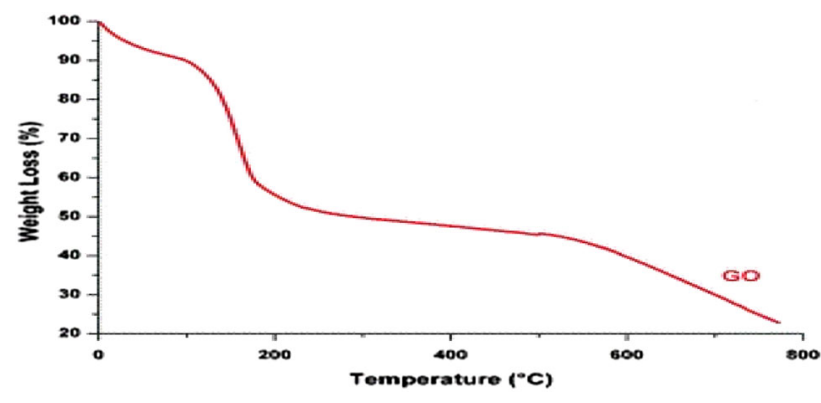

Fig. 4 Thermogravimetric analysis (TGA) of graphene oxide

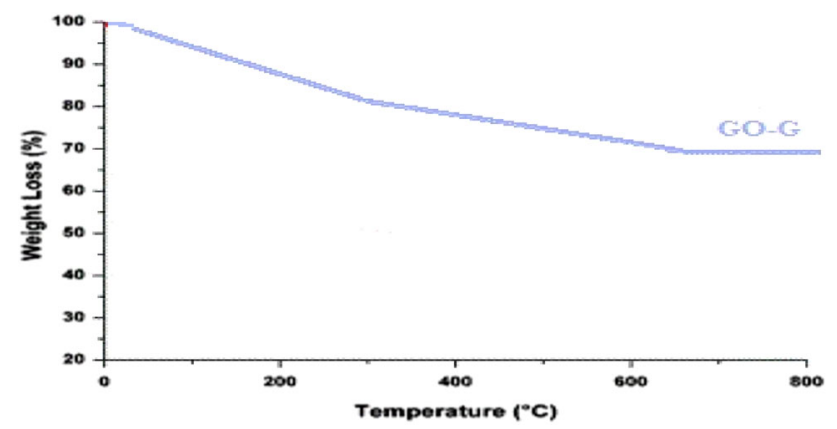

Fig. 5 Thermogravimetric analysis (TGA) of graphene oxide-glycine nanocomposites

\section{Thermal gravity analysis for the stability of graphene oxide-glycine nanocomposites (TGA studies)}

The decomposition behaviors of $\mathrm{GO}$ and $\mathrm{GO}-\mathrm{G}$ nanocomposites have been investigated by thermal gravity analysis. Figure 4 shows the thermal stability of the GO, which is relatively good, but at a temperature of about $200{ }^{\circ} \mathrm{C}$, the thermal stability of GO was found to decrease. due to the decomposition of carboxylic and release of $\mathrm{CO}_{2}$ gas.

But as seen in Fig. 5, the GO-G nanocomposites have less thermal stability than GO. Because nanocomposite $\mathrm{GO}-\mathrm{G}$, in addition to the withdrawal of $\mathrm{CO}_{2}$ gas from the molecular structure, structure of nanocomposite with increasing temperature decomposed and nitrogen gas, carbon dioxide gas, etc., will be withdrawal from the molecule of nanocomposite GO-G [13-15].

\section{Conclusions}

In this study, we investigated the stability of $\mathrm{GO}-\mathrm{G}$ nanocomposites by thermal gravity analysis. In order to study the thermal stability, we synthesized nanocomposite by performing reaction between dry powder of GO and glycine. Results of characterization by SEM and FT-IR showed that nanocomposite was created by the reaction between GO and glycine. Then, we used TGA and found that the thermal stability of GO is more than that of the GO-G nanocomposites.

Acknowledgments The author would like to thank the Islamic Azad, Roudehen Branch for their financial support.

Open Access This article is distributed under the terms of the Creative Commons Attribution 4.0 International License (http:// creativecommons.org/licenses/by/4.0/), which permits unrestricted use, distribution, and reproduction in any medium, provided you give appropriate credit to the original author(s) and the source, provide a link to the Creative Commons license, and indicate if changes were made.

\section{References}

1. Ye, X., Du, Y., Lu, D., Wang, C.: Fabrication of $\beta$-cyclodextrincoated poly (diallyldimethylammonium chloride)-functionalized graphene composite film modified glassy carbon-rotating disk electrode and its application for simultaneous electrochemical determination colorants of sunset yellow and tartrazine. Anal. Chim. Acta 779, 22-34 (2013)

2. Singh, V., Joung, D., Zhai, L., Das, S., Khondaker, S.I., Seal, S.: Graphene based materials: past, present and future. Prog. Mater. Sci. 56(8), 1178-1271 (2011)

3. Fan, Z., Wang, K., Wei, T., Yan, J., Song, L., Shao, B.: An environmentally friendly and efficient route for the reduction of graphene oxide by aluminum powder. Carbon 48(5), 1686-1689 (2010)

4. Thakur, S., Karak, N.: Green reduction of graphene oxide by aqueous phytoextracts. Carbon 50(14), 5331-5339 (2012)

5. Thema, F.T., Moloto, M.J., Dikio, E.D., et al.: Synthesis and characterization of graphene thin films by chemical reduction of exfoliated and intercalated graphite oxide. J. Chem. (2012). doi: $10.1155 / 2013 / 150536$

6. Zhang, H., Feng, P.X.: Fabrication and characterization of fewlayer graphene. Carbon 48(2), 359-364 (2010)

7. Algothmi, W.M., Murthy Bandaru, N., Yu, Y., Shapter, J.G., Ellis, A.V.: Alginate-graphene oxide hybrid gel beads: an efficient copper adsorbent material. J. Colloid Interface Sci. 397, 32-38 (2013)

8. Nomenclature and symbolism for amino acids and peptides (Recommendations 1983). Pure Appl. Chem. 56, 595-624 (1984)

9. Coyle, J.T., Tsai, G.: The NMDA receptor glycine modulatory site: a therapeutic target for improving cognition and reducing negative symptoms in schizophrenia. Psychopharmacology 174, 28-32 (2004)

10. Jönsson, P.G., Kvick, Å.: Precision neutron diffraction structure determination of protein and nucleic acid components III. The crystal and molecular structure of the amino acid -glycine. Acta Crystallogr. Sect. B 28(6), 1827-1833 (1972)

11. Yamadera, W., Inagawa, K., Chiba, S., Bannai, M., Takahashi, M., Nakayama, K.: Glycine ingestion improves subjective sleep quality in human volunteers, correlating with polysomnographic changes. Sleep Biol. Rhythm. 5(2), 126-131 (2007)

12. Kamigaito, O.: What can be improved by nanometer composites. J. Jpn. Soc. Powder Powder Metall. 38(3), 315-319 (1991) 
13. Kumar, A., Khandelwal, M.: Amino acid mediated functionalization and reduction of graphene oxide - synthesis and the formation mechanism of nitrogen-doped graphene. N. J. Chem. 38, 3457-3467 (2014)

14. Chun Kiang Chua and Martin Pumera: Chemical reduction of graphene oxide: a synthetic chemistry viewpoint. Chem. Soc. Rev. 43, 291-312 (2014)
15. Wang, T., Wang, L., Wu, D., Xia, W., Zhao, H., Jia, D.: Hydrothermal synthesis of nitrogen-doped graphene hydrogels using amino acids with different acidities as doping agents. J. Mater. Chem. A 2, 8352-8361 (2014) 